\title{
Análisis complejo del discurso. Una propuesta metodológica para el estudio de la representación mediática en la prensa escrita'
}

\author{
Mg. Alberto Javier Mayorga Rojel* \\ Dr. Carlos del Valle Rojas** \\ Mg. Luis Nitrihual Valdebenito***
}

Recibido: 6 de septiembre de 2008

Aprobado: 8 de octubre de 2008

\section{Resumen}

Este artículo presenta una propuesta metodológica de análisis complejo del discurso que permite comprender, en el marco de la producción de sentido que el discurso como acción comunicativa simbólica genera de manera progresiva, la representación mediática que elaboró la prensa chilena acerca de un Estado-nación (Perú) y que, a lo largo del tiempo, cimienta en las audiencias un reforzamiento ideológico del conocimiento social que ha sido configurado en el proceso socializador de una nación.

\section{Palabras clave}

Análisis complejo del discurso, representaciones, medios de comunicación.

Académico de la carrera de Periodismo y del magíster en Ciencias de la Comunicación. Departamento de Lenguas, Literatura y Comunicación Facultad de Educación y Humanidades. Universidad de La Frontera. Temuco - Chile. Doctorando en Ciencia Política. Becario Fundación Volcán Calbuco. Email: amayorga@ufro.cl

** Decano de la Facultad de Educación y Humanidades. Universidad de La Frontera. Temuco - Chile. Casilla 54-D (Temuco - Chile). Email: delvalle@ufro.cl.

*** Académico de la carrera de Periodismo y del magíster en Ciencias de la Comunicación. Departamento de Lenguas, Literatura y Comunicación. Facultad de Educación y Humanidades. Universidad de La Frontera. Temuco - Chile. Casilla 54-D (Temuco - Chile). Becario del Fondo Nacional del Libro y La Lectura para estudios de postgrado en el extranjero 2008. Email: anitrihual@ufro.cl. 


\title{
Complex analysis of the discourse. A methodological proposal for studying media representation in written press
}

\begin{abstract}
This article presents a methodological proposal of a complex analysis of the discourse, which allows understanding, for the production of sense which discourse as a communicative symbolic action generates on a progressive basis, media representation which Chilean press prepared about a State-Nation (Peru) and that, along the time, consolidates in audiences an ideological strengthening of the social knowledge which has been configured during the socializing process of a nation.
\end{abstract}

\section{Key words}

Complex analysis of the discourse, representations, communication media. 


\section{INTRODUCCIÓN}

Al analizar el producto informativo que produce la prensa escrita de Chile en lo que respecta al conflicto marítimo de 2005 entre Chile y Perú, debemos comprender, a modo de pilar teórico fundamental para el presente artículo, que el discurso periodístico es una forma de representar el conocimiento de algo y, por lo tanto, la acción social de construir una realidad es propia del proceso discursivo donde el significado y las prácticas significativas se realizan. Además, es factible asumir que el discurso es el reflejo de una lucha interna entre significados dominantes y dominados, entre las estrategias de construcción del sentido de los múltiples contenidos expuestos y las variadas interpretaciones que puede hacer el destinatario al tomar como elemento referencial las propias experiencias. Así, la producción y distribución del discurso permite a las instituciones mediáticas y a los Estados latinoamericanos trabajar en conjunto para mantener el poder que los faculta para generar realidad y conocimiento en las audiencias.

Sin embargo, debemos tener absoluta claridad de que el discurso generado por la prensa sobre Perú en el marco del mencionado conflicto no está únicamente constituido por un conjunto determinado de imágenes que se sustentan en abstracciones complejas de sentido sino que, además, éste se conforma a partir de la dimensión histórica asociada a los hechos ocurridos en el pasado y que se complementa en el presente con una se- cuencia de acciones políticas llevadas a cabo por las autoridades de cada gobierno en el marco de la interacción discursiva mediática, generada tanto por un sujeto político como por el colectivo social que conforma la opinión pública de los respectivos países.

En este contexto político, económico, histórico y cultural que se vislumbra complejo por el camino que han tomado las relaciones internacionales en América Latina, la investigación centró su interés en el análisis de los discursos que la prensa de Chile elaboró en torno a este momento de gran expectación pública y que se clasifica como un conflicto diplomático que se establece sobre la base de determinadas desavenencias entre los países. Estas discrepancias entre Estados que merman las relaciones internacionales y las confianzas diplomáticas, producen una serie de hechos noticiosos y declaraciones públicas por parte de las autoridades de gobierno de ambos países, lo que permite a los medios de comunicación cubrir el conflicto y elaborar discursos donde se pueden identificar con mayor facilidad ciertas estrategias discursivas que esconden una actitud racista, un sentido de superioridad, exclusión, menosprecio y valoración negativa de capacidades políticas y económicas, entre otras.

En consecuencia, el objetivo del presente artículo es presentar un modelo dimensional de análisis complejo del discurso periodístico que permite comprender, en el marco de la producción de sentido que el discurso como acción comunicativa simbólica genera de 
manera progresiva, la representación mediática que elaboró la prensa chilena sobre un Estado-nación (Perú) y que, a lo largo del tiempo, cimienta en las audiencias un reforzamiento ideológico del conocimiento social que ha sido configurado en el proceso socializador de una nación.

\section{MARCO TEÓRICO}

Sin duda que los diversos discursos producidos por los medios de comunicación en el marco de las relaciones internacionales entre los gobiernos de Perú y Chile han desencadenado una serie de acciones sociales que se enmarcan dentro del sistema político, económico y social de ambas naciones. Así, los discursos mediáticos y políticos que corresponden al Estado de Chile y que son producidos por las autoridades, tanto de gobierno como de oposición, se pueden clasificar como un mecanismo estratégico que busca perpetuar el sentido común en torno a la presencia (amenazante» del Otro y, de esta manera, fortalecer el poder de las clases dominantes por medio de la configuración tautológica y permanente de las visiones sobre la realidad.

A su vez, debemos tener absoluta claridad de que el discurso mediático que se genera a partir de las relaciones internacionales no está únicamente constituido por un conjunto determinado de proposiciones que se sustentan en abstracciones complejas de sentido sino que, además, éste se conforma a partir de una secuencia -a modo de efecto dominó- de acciones políticas en el marco de la interacción discursiva generada tanto por el sujeto como por el colectivo de ambos países.

Lo anterior nos permite aventurarnos desde una perspectiva crítica- a enarbolar una idea que alude a que en el marco de las relaciones discursivas, la representación del mundo, particularmente del Perú, ha sido construida sobre la base de elementos de significación discriminatorios que producen una representación textual de intolerancia acerca del Otro que es vinculado con implicaciones de carácter negativo para el desarrollo del país y donde las manifestaciones políticas y mediáticas de diversa índole, llevadas a cabo por un sujeto o colectivo que representa a la nación peruana, se clasifican como acciones que atentan contra el orden socioeconómico y político establecido para el bienestar del pueblo chileno.

De este modo, las representaciones del discurso político y mediático, centradas en la diversidad del escenario internacional latinoamericano, gestan un sistema ordenado de referencia dominante que pretende otorgar un sentido homogéneo al mundo social como mecanismo utilizado para mantener categorías históricas acerca del Otro. Por lo tanto, la acción discursiva de los mass media tiende a producir una ultrasimplificación sígnica de un Estadonación por medio de la producción de esquemas interpretativos capaces de facilitar al colectivo dominante la distinción entre el «Nosotros»y los «Otros».

Ahora, las representaciones sustentadas en un principio ideológico que logra modificar el discurso político y mediático tienen la facultad de categorizar al colectivo exógeno ${ }^{2}$ sobre la base de creencias 
compartidas socioculturalmente en los grupos dominantes y, de esta manera, se pretende establecer un discurso verosímil capaz de reforzar en la memoria histórica las imágenes que se han transmitido por medio de las diversas operaciones socializadoras de cada sociedad.

Para Manuel Martín Serrano -en el contexto de las visiones que pueden llegar a producir los diversos aparatos ideológicoslas representaciones que se configuran acerca de la realidad:

«ofrecen un modelo del mundo reconocible en el entorno o tácticamente posible; sugieren a los actores comportamientos factibles y aceptados; y describen situaciones que suelen ser las más probables» (Martín Serrano, 1986, p. 44).

De esta manera, la condición ideológica de los medios de comunicación determina la configuración de un objeto duplicado in absentia del objeto real y se establece una mímesis sobre la base de la presencia (simulación) de algunas propiedades del objeto representado (Lefebvre, 1983). A partir de lo descrito, se puede observar que los medios de comunicación elaboran discursos donde los significados que se adscriben a los acontecimientos del presente, siempre están alineados -en la medida que se relacionen con los objetivos e intenciones del enunciador- a las representaciones del pasado y, por ende, la producción de significados apunta a la correlación entre las imágenes propuestas por la dimensión histórica y las representaciones producidas por las instituciones que controlan las múltiples instancias de socialización a partir de las lógicas de poder imperante en el mundo actual. En caso contrario, los mass media generan discursos conformados por una matriz de significados nuevos que se contraponen a las representaciones del pasado y, en consecuencia, los nuevos relatos pretenden institucionalizar una determinada interpretación de lo que acontece.

Esta acción de imponer una nueva interpretación en el marco de las relaciones sociales discursivas se entiende como la búsqueda vital por el control social por parte de las instituciones -como es el caso de los grupos económicos y mediáticos que se agrupan para compartir una ideología específica- de tal forma que éstas establecen estrategias comunicacionales con la finalidad de mantener el control sobre las relaciones simbólicas que se perpetúan en los múltiples discursos mediáticos engendrados sobre la base de una construcción artificial capaz de estimular e influir a las audiencias para aceptar una representación como legítima y verdadera. Este panorama que se construye a partir del conocimiento que poseen los grupos de poder sobre los patrones de lecturas utilizados por los sujetos evidencia el propósito fundamental -desde la lógica funcional de los medios de comunicación- por instaurar un orden institucional-ideológico que permita reforzar, por una parte, la legitimidad de las representaciones dispuestas en los discursos mediáticos y, por otra, los límites de interpretación necesarios para enmarcar -desde la visión dominante de los acontecimientos - los significados favorables al relato periodístico institucional (Van Dijk, 1999). 
Este imperativo organizacional centrado en el control social que se busca ejercer -en general - por parte de las instituciones sociales de poder y -en particular- por los medios de comunicación social, se sustenta en la configuración de representaciones de la realidad que, desde la perspectiva teórica planteada por Martín Serrano (1986, p. 45), deben satisfacer dos necesidades:

\section{Proporciona una teoría de la socie-} dad. Esto se traduce como la necesidad de mantener la organización social favorable para el control social y conservar el orden de las instituciones, lo que permitirá armonizar las transformaciones de las formas de vida y de los valores que se circunscriben a la norma dominante.

\section{Proporciona en el nivel subjetivo} gratificaciones cognitivas y afectivas. Esta necesidad se entiende como la capacidad que debe poseer el modelo ideológico para lograr el reconocimiento y aceptación de la interpretación que se hace del mundo por parte de la sociedad. Aquí se puede evaluar si existe un control social eficiente al contemplar en los sujetos la satisfacción de sus necesidades vinculadas a la personalidad: a) conciencia de pertenencia a un grupo, y b) sentimiento de seguridad.

Frente a estas necesidades, los medios de comunicación social reconocen el sistema sociocultural de signos que se articulan entre sí y acceden a las condiciones exigidas para la interacción social en una comunidad lingüística específica, normas de comportamiento y convenciones que existen en un grupo social. Todo esto con el objetivo institucional de lograr una mediación como forma de intervenir en la elaboración de representaciones.

\section{PROPUESTA METODOLÓGICA}

El análisis complejo del discurso que se utilizó para desarrollar la investigación acerca de la representación mediática del Perú, en el discurso periodístico de los diarios El Mercurio y La Tercera, está construido sobre la base de las perspectivas teóricas trabajadas por J. Courtés (1995), J -C. Giroud y L. Panier (1988), en el marco del análisis semiótico textual, y por medio de las ideas de J. Potter (1998), quien propone identificar las representaciones discursivas a partir de las factualidades reconocibles en todo texto, las cuales han sido re-elaboradas desde la perspectiva teórico-metodológica trabajada por Del Valle (2006, p.p 169 179).

De esta forma, en la investigación se aplicó un análisis complejo del discurso que nos permitió estudiar los textos que la prensa publicó a partir de la cobertura del conflicto entre dos Estados-nación (Chile y Perú).

Por lo tanto, 19 noticias de portada corresponden al total de discursos periodísticos publicados por El Mercurio (10 noticias) y La Tercera (9 noticias), durante la cobertura del conflicto limítrofe-marítimo de 2005 entre Chile y Perú. Las noticias publicadas en portada entre el viernes 28 de octubre y el domingo 6 de noviembre de 2005 fueron seleccionadas de acuerdo con los siguientes criterios: 


\begin{tabular}{|l|l|}
\hline a. Género & Informativo y/o Interpretativo \\
\hline b. Sección & Portada \\
\hline c. Períodos & Octubre y noviembre de 2005 \\
\hline d. Temporalidad & $\begin{array}{l}\text { Noticias publicadas a partir del 28 de octubre al } \\
\text { 6 de noviembre de 2005. }\end{array}$ \\
\hline e. Tópicos o temas & $\begin{array}{l}\text { Conflicto limítrofe-marítimo entre Chile y Perú que } \\
\text { se gesta a partir de la ley aprobada por el Con- } \\
\text { greso del Perú para el establecimiento de nuevas } \\
\text { líneas de base del dominio marítimo. }\end{array}$ \\
\hline f. Participantes o actores $\quad$ recurrentes & $\begin{array}{l}\text { Presidente de Perú, Presidente de Chile, Minis- } \\
\text { tros de Relaciones Exteriores de ambos países, } \\
\text { Embajadores, Congresistas, Ministro Secretario } \\
\text { General del Gobierno de Chile, Ministro de De- } \\
\text { fensa de Chile, }\end{array}$ \\
\hline
\end{tabular}

Tabla - Criterios de Selección.

Fuente: Elaborado por los autores para la investigación.

Cabe destacar entonces que la investigación analizó un corpus extraído de los diarios El Mercurio y La Tercera. Ambos medios de comunicación fueron seleccionados por su cobertura nacional y por tener -en el primer caso- la mayor circulación en nuestro país y -en el segundo caso- por tener el cuarto lugar en el promedio de circulación en comparación con otros diarios existentes en Chile. Sin embargo, lo anterior se complementa con la importancia que tienen ambos diarios en la configuración de la opinión pública en Chile y los niveles de lectoría que ostenta cada producto informativo.

Por consiguiente, a modo de justificación estadística, es factible indicar que según los datos proporcionados por el Sistema de Verificación de Circulación y Lectoría (20052006), en el cual participan la Asociación Nacional de Avisadores (ANDA), la Asociación Chilena de Agencias de Publicidad (Achap) y los principales diarios pagados y gratuitos del país, El Mercurio cuenta con un promedio de 381.125 lectores semanales, lo cual aumenta durante los fines de semanas a 491.125. De la misma forma, el diario La Tercera cuenta con un promedio de 303.881 lectores semanales lo cual aumenta durante los fines de semanas a 417.105.

\section{Modelo de análisis complejo del discurso}

El modelo de análisis complejo del discurso utilizado en el estudio de la representación mediática procura descubrir, revelar o divulgar conexiones que a menudo se encuentran implícitas en los discursos y, en consecuencia, el modelo trabaja sobre manifestaciones explícitas e implícitas existentes en los textos, como es el caso de los actores, roles, lugares simbólicos, valores temáticos, situaciones discursivas, fabricación de consensos, recorridos figurativos, lógicas de poder y matrices ideológicas. 


\begin{tabular}{|l|l|}
\hline \multicolumn{2}{|c|}{ DIMENSIÓN DISCURSIVA } \\
\hline FIGURAS & $\begin{array}{l}\text { Las figuras son elementos de significación más o menos deter- } \\
\text { minados, pero reconocibles en la lectura. Se dividen en actores, } \\
\text { tiempo y lugares. }\end{array}$ \\
\hline RECORRIDOS FIGURATIVOS & $\begin{array}{l}\text { Las figuras están dispuestas en recorridos figurativos. Esto se } \\
\text { debe entender como el modo en que el texto utiliza las figuras y } \\
\text { la manera como se desarrolla una figura en el texto. }\end{array}$ \\
\hline VALORES TEMÁTICOS & $\begin{array}{l}\text { Es el sentido que se construye a partir de las relaciones entre las } \\
\text { figuras y sus recorridos figurativos. Por lo tanto, las figuras tie- } \\
\text { nen un valor a partir de su relación con otras figuras. Es la espe- } \\
\text { cificidad de las figuras, es decir, el papel que cumple cada una en } \\
\text { el texto. }\end{array}$ \\
\hline SITUACIONES DISCUSIVAS & $\begin{array}{l}\text { Todo texto dispone a los actores en un(os) tiempo(s) y en un (os) } \\
\text { lugar(es), permitiendo esta disposición la lectura de un texto a } \\
\text { partir de la identificación de situaciones discursivas (relaciones } \\
\text { entre figuras). }\end{array}$ \\
\hline
\end{tabular}

Fuente: Elaborado por los autores para la investigación.

\begin{tabular}{|c|c|}
\hline \multicolumn{2}{|r|}{ DIMENSIÓN FACTUAL } \\
\hline DISCURSO EMPIRISTA & $\begin{array}{l}\text { «... no se limita a centrarse en los datos sino que los construye } \\
\text { como si tuvieran una agencia propia» (Potter, 1998, p. 152). }\end{array}$ \\
\hline FABRICACIÓN DEL CONSENSO & $\begin{array}{l}\text { «... los participantes tienden a construir corroboración cuando } \\
\text { elaboran y socavan relatos [pues] los procedimientos para la } \\
\text { construcción de hechos no trabajan de manera aislada. Tienen } \\
\text { la misma probabilidad de que se recurra a ellos conjuntamente» } \\
\text { (Potter, 1998, p. 152-153). }\end{array}$ \\
\hline DETALLES EN LA NARRACIÓN & $\begin{array}{l}\text { «Los datos específicos de una descripción son cruciales para la } \\
\text { actividad a la que se destina la descripción lyl son descripciones } \\
\text { detalladas con minuciosidad» (Potter, 1998, p. 154). } \\
\text { «La formulación de 'casos extremos' ly] que consiste en utilizar } \\
\text { los extremos de las dimensiones descriptivas pertinentes» (Potter, } \\
\text { 1998, p. 238). }\end{array}$ \\
\hline $\begin{array}{l}\text { MAXIMIZACIÓN / } \\
\text { MINIMIZACIÓN } \\
\text { NORMALIZACIÓN / } \\
\text { ANORMALIZACIÓN }\end{array}$ & $\begin{array}{l}\text { «... describir una acción que, por consenso, se considera anor- } \\
\text { mal o extraña [utilizando] una organización discursiva que des- } \\
\text { cribe una actividad y que, al mismo tiempo, proporciona pistas } \\
\text { para verla como anormal o extraña [por lo cuall la cuestión de la } \\
\text { anormalidad está estrechamente vinculada con la cuestión de la } \\
\text { regularidad» (Potter, 1998, p. 247-248). }\end{array}$ \\
\hline
\end{tabular}

Fuente: Elaborado por los autores para la investigación. 


\section{DIMENSIÓN SEMIÓTICA}

(CUADRADO SEMIÓTICO)

\begin{tabular}{|c|c|c|c|c|}
\hline \multicolumn{2}{|c|}{ RELACIONES DE CONTRARIEDAD } & \multicolumn{3}{|c|}{ Relación lógica entre A y B, y entre NO B y NO A. } \\
\hline \multicolumn{2}{|c|}{ RELACIONES DE CONTRADICCIÓN } & \multicolumn{3}{|c|}{ Relación lógica entre A y NO A, y entre B y NO B. } \\
\hline \multicolumn{2}{|l|}{$\begin{array}{l}\text { RELACIONES DE } \\
\text { COMPLEMENTARIEDAD }\end{array}$} & \multicolumn{3}{|c|}{ Relación lógica entre A y NO B, y B y NO A. } \\
\hline A & \multicolumn{2}{|c|}{ NO A } & B & NO B \\
\hline $\begin{array}{l}\text { Representación lógica } \\
\text { del SER. }\end{array}$ & \multicolumn{2}{|c|}{$\begin{array}{l}\text { Representación lógica } \\
\text { del NO SER. }\end{array}$} & $\begin{array}{l}\text { Representación lógica } \\
\text { del PARECER. }\end{array}$ & $\begin{array}{l}\text { Representación lógica } \\
\text { del NO PARECER. }\end{array}$ \\
\hline
\end{tabular}

Fuente: Elaborado por los autores para la investigación.

\section{Aplicación del modelo de análisis complejo del discurso}

A continuación se presenta - a modo de ejemplo - el análisis discursivo de un texto periodístico publicado por el diario La Tercera (sábado 29 de octubre de 2005) en el marco de la cobertura mediática del conflicto diplomático.

\section{Dimensión discursiva}

\section{TITULAR}

«Gobierno califica como delicado intento de Perú por cambiar límite marítimo»

\begin{tabular}{|l|l|l|}
\hline \multicolumn{1}{|c|}{ FIGURA } & RECORRIDO FIGURATIVO & \multicolumn{1}{|c|}{ VALORTEMÁTICO } \\
\hline $\begin{array}{l}\text { La Moneda } \\
\text { (Figura actor) }\end{array}$ & $\begin{array}{l}\text { Representación del gobierno de } \\
\text { Chile. Se manifiesta preocupada } \\
\text { y alerta frente a la situación limí } \\
\text { trofe desencadenada con Perú. }\end{array}$ & $\begin{array}{l}\text { - Inseguridad } \\
\text { - Prestabilidad } \\
\text { Prevención }\end{array}$ \\
\hline $\begin{array}{l}\text { (Figura tiempo) } \\
\text { (Fión }\end{array}$ & $\begin{array}{l}\text { Fecha en la cual se aprueba en el } \\
\text { Congreso peruano el proyecto de } \\
\text { ley de Líneas de Base. }\end{array}$ & $\begin{array}{l}\text { - Polémica } \\
\text { Tensión } \\
\text { Conflicto }\end{array}$ \\
\hline $\begin{array}{l}\text { Comisión de Relaciones Exterio- } \\
\text { res del Congreso Peruano } \\
\text { (Figura actor) }\end{array}$ & $\begin{array}{l}\text { Comisión legislativa que aprue } \\
\text { ba de forma unánime el proyec- } \\
\text { to de Ley de Líneas de Base. }\end{array}$ & $\begin{array}{l}\text { - Conflicto } \\
\text { Crisis } \\
\text { Unilateralidad } \\
\text { Arbitrariedad }\end{array}$ \\
\hline
\end{tabular}

Fuente: Elaborado por los autores para la investigación. 


\begin{tabular}{|c|c|c|}
\hline $\begin{array}{l}\text { Ley de Líneas de Base } \\
\text { (Figura actor) }\end{array}$ & $\begin{array}{l}\text { Proyecto de ley impulsado por el } \\
\text { gobierno de Alejandro Toledo y } \\
\text { que fija nuevos puntos de refe- } \\
\text { rencia sobre los cuales delimitan } \\
\text { en el Pacífico Chile y Perú. }\end{array}$ & $\begin{array}{l}\text { - Conflicto } \\
\text { - Modificación } \\
\text { - Inseguridad } \\
\text { - Tensión } \\
\text { - Quebrantamiento }\end{array}$ \\
\hline $\begin{array}{l}\text { Zona del Pacífico } \\
\text { (Figura lugar) }\end{array}$ & $\begin{array}{l}\text { Zona que Perú pretende modifi- } \\
\text { car a través de la Ley de Líneas } \\
\text { de Bases, consistente en expan- } \\
\text { dir su territorialidad sobre la zona } \\
\text { del respectivo océano sobre la } \\
\text { cual Chile posee la jurisdicción. }\end{array}$ & $\begin{array}{l}\text { - Polémica } \\
\text { - Disputa } \\
\text { - Riqueza }\end{array}$ \\
\hline $\begin{array}{l}\text { Perú } \\
\text { (Figura actor) }\end{array}$ & $\begin{array}{l}\text { País de Sudamérica que limita } \\
\text { con Chile y el cual pretende mo- } \\
\text { dificar el límite marítimo con este } \\
\text { país a través de la Ley de Líneas } \\
\text { de Base. }\end{array}$ & $\begin{array}{l}\text { - Unilateralidad } \\
\text { - Desconocimiento } \\
\text { - Infracción } \\
\text { - Tensión } \\
\text { - Pretensión } \\
\text { - Reclamo }\end{array}$ \\
\hline $\begin{array}{l}\text { Ricardo Lagos Escobar } \\
\text { (Figura actor) }\end{array}$ & $\begin{array}{l}\text { Presidente de la República de } \\
\text { Chile. Se reúnen en el Palacio de } \\
\text { gobierno con los ministros de } \\
\text { Defensa, Relaciones Exteriores, } \\
\text { del Interior y Secretaría General } \\
\text { de la Presidencia, con el objetivo } \\
\text { de analizar la situación diplomá- } \\
\text { tica con el país vecino. }\end{array}$ & $\begin{array}{l}\text { - Preocupación } \\
\text { - Análisis } \\
\text { - Inseguridad } \\
\text { - Malestar } \\
\text { - Descontento }\end{array}$ \\
\hline $\begin{array}{l}\text { Ministros del gobierno de Chile } \\
\text { (Figura actor) }\end{array}$ & $\begin{array}{l}\text { El Canciller (s) Cristián Barros, el } \\
\text { ministro de Defensa, Jaime } \\
\text { Ravinet, el ministro del Interior, } \\
\text { Francisco Vidal, el secretario ge- } \\
\text { neral de la Presidencia, Eduardo } \\
\text { Dockendorff y el secretario ge- } \\
\text { neral de Gobierno, Osvaldo } \\
\text { Puccio, se reúnen con el Presi- } \\
\text { dente de la República con el } \\
\text { objetivo de analizar la situación } \\
\text { desencadenada por la aproba- } \\
\text { ción del proyecto de ley por par- } \\
\text { te del Congreso peruano. }\end{array}$ & $\begin{array}{l}\text { - Diplomacia } \\
\text { - Apoyo } \\
\text { - Análisis } \\
\text { - Disconformidad } \\
\text { - Inquietud }\end{array}$ \\
\hline $\begin{array}{l}\text { Osvaldo Puccio } \\
\text { (Figura actor) }\end{array}$ & $\begin{array}{l}\text { Secretario general de Gobierno. } \\
\text { Califica la situación como un } \\
\text { «tema delicado» y sostiene que } \\
\text { Chile espera que se mantengan } \\
\text { los tratados vigentes de delimi- } \\
\text { tación con Perú. }\end{array}$ & $\begin{array}{l}\text { - Concilio } \\
\text { - Calma } \\
\text { - Apaciguo }\end{array}$ \\
\hline
\end{tabular}




\begin{tabular}{|c|c|c|}
\hline $\begin{array}{l}\text { Torre Tagle } \\
\text { (Figura actor) }\end{array}$ & $\begin{array}{l}\text { Representación del gobierno de } \\
\text { Perú. A través de la aprobación } \\
\text { de la Ley de Líneas de Base, con- } \\
\text { siderada como una «estrategia ju- } \\
\text { rídica», Perú pretende reclamar } \\
\text { ante tribunales internacionales la } \\
\text { modificación de límites maríti- } \\
\text { mos con Chile. }\end{array}$ & $\begin{array}{l}\text { - Conflicto } \\
\text { - Quebrantamiento } \\
\text { - Tensión } \\
\text { - Unilateralidad } \\
\text { - Hostilidad }\end{array}$ \\
\hline $\begin{array}{l}\text { Bolivia } \\
\text { (Figura actor) }\end{array}$ & $\begin{array}{l}\text { País involucrado dentro del con- } \\
\text { flicto de delimitación marítima } \\
\text { entre Chile y Perú, por cuanto, de } \\
\text { aprobarse la modificación limí- } \\
\text { trofe, Bolivia vería sepultados los } \\
\text { deseos de obtener un acceso } \\
\text { soberano al océano Pacífico. }\end{array}$ & $\begin{array}{l}\text { - Víctima } \\
\text { - Perjuicio } \\
\text { - Preocupación } \\
\text { - Intranquilidad } \\
\text { - Incertidumbre }\end{array}$ \\
\hline $\begin{array}{l}\text { Tratado de Zona de Delimitación } \\
\text { Marítima } \\
\text { (Figura actor) }\end{array}$ & $\begin{array}{l}\text { Tratado firmado entre Chile, Perú } \\
\text { y Ecuador en } 1952 \text { y que fija la } \\
\text { actual delimitación entre estos } \\
\text { países.La postura oficial de Chi- } \\
\text { le se basa en la invocación de la } \\
\text { vigencia del respectivo Tratado. }\end{array}$ & $\begin{array}{l}\text { - Legalidad } \\
\text { - Convenio } \\
\text { - Exactitud } \\
\text { - Formalismo }\end{array}$ \\
\hline $\begin{array}{l}\text { Ecuador } \\
\text { (Figura actor) }\end{array}$ & $\begin{array}{l}\text { País que junto a Chile y Perú fir- } \\
\text { man el Tratado de Delimitación } \\
\text { Marítima en } 1952 .\end{array}$ & $\begin{array}{l}\text { - Implicado } \\
\text { - Inseguridad } \\
\text { - Complicación }\end{array}$ \\
\hline $\begin{array}{l}\text { Ministerio de Defensa de Chile } \\
\text { (Figura actor) }\end{array}$ & $\begin{array}{l}\text { De acuerdo con informes entre- } \\
\text { gados por esta cartera ministe- } \\
\text { rial, de modificarse el límite ma- } \\
\text { rítimo, significaría que buques } \\
\text { peruanos puedan navegar en te- } \\
\text { rritorio chileno, situación que } \\
\text { obligaría a una reacción por par- } \\
\text { te de la Armada. }\end{array}$ & $\begin{array}{l}\text { - Alerta } \\
\text { - Peligro } \\
\text { - Inestabilidad } \\
\text { - Tensión }\end{array}$ \\
\hline $\begin{array}{l}\text { Alejandro Toledo } \\
\text { (Figura actor) }\end{array}$ & $\begin{array}{l}\text { Presidente de Perú e impulsor de } \\
\text { la Ley de Líneas de Base. En su } \\
\text { calidad de mandatario participa- } \\
\text { rá en la Cumbre de Las Améri- } \\
\text { cas, próxima a realizarse en la } \\
\text { ciudad de Mar del Plata. }\end{array}$ & $\begin{array}{l}\text { - Hostilidad } \\
\text { - Tensión } \\
\text { - Inestabilidad } \\
\text { - Conflicto }\end{array}$ \\
\hline
\end{tabular}




\begin{tabular}{|c|c|c|}
\hline $\begin{array}{l}\text { Cumbre de las Américas } \\
\text { (Figura actor) }\end{array}$ & $\begin{array}{l}\text { Reunión de jefes de Estado y de } \\
\text { Gobierno auspiciada por la Orga- } \\
\text { nización de los Estados Ameri- } \\
\text { canos, la cual tiene como objeti- } \\
\text { vo formar una estrategia común } \\
\text { para resolver los problemas de la } \\
\text { región. }\end{array}$ & $\begin{array}{l}\text { - Diplomacia } \\
\text { - Consenso } \\
\text { - Arbitraje - Apoyo } \\
\text { - Negociación } \\
\text { - Compromiso }\end{array}$ \\
\hline $\begin{array}{l}\text { Libro Blanco de Defensa Nacio- } \\
\text { nal } \\
\text { (Figura actor) }\end{array}$ & $\begin{array}{l}\text { Durante el año } 2004 \text {, el gobierno } \\
\text { peruano informa que incluirá, en } \\
\text { el Libro Blanco de Defensa Na- } \\
\text { cional, su intención de realizar } \\
\text { estudios para establecer defini- } \\
\text { tivamente los límites con Chile. }\end{array}$ & $\begin{array}{l}\text { - Pretensión } \\
\text { - Modificación } \\
\text { - Tensión }\end{array}$ \\
\hline $\begin{array}{l}\text { Manuel Rodríguez Cuadros } \\
\text { (Figura actor) }\end{array}$ & $\begin{array}{l}\text { Canciller peruano, quien duran- } \\
\text { te el año } 2004 \text { plantea la posibi- } \\
\text { lidad de recurrir a un arbitraje in- } \\
\text { ternacional frente a la } \\
\text { modificación limítrofe con Chile. }\end{array}$ & $\begin{array}{l}\text { - Tensión } \\
\text { - Hostilidad } \\
\text { - Alteración }\end{array}$ \\
\hline $\begin{array}{l}\text { Soledad Alvear } \\
\text { (Figura actor) }\end{array}$ & $\begin{array}{l}\text { Ex Canciller de la República de } \\
\text { Chile. Frente al planteamiento } \\
\text { peruano de recurrir a un arbitra- } \\
\text { je internacional, en el } 2004 \text { plan- } \\
\text { tea que para Chile no existen te- } \\
\text { mas pendientes en materia } \\
\text { limítrofe. }\end{array}$ & $\begin{array}{l}\text { - Disconformidad } \\
\text { - Malestar } \\
\text { - Seguridad } \\
\text { - Firmeza } \\
\text { - Solidez }\end{array}$ \\
\hline $\begin{array}{l}\text { Tribunal Internacional de La Haya } \\
\text { (Figura actor) }\end{array}$ & $\begin{array}{l}\text { Es una denominación que ha } \\
\text { sido utilizada para designar diver- } \\
\text { sos tribunales internacionales } \\
\text { que tienen o han tenido su sede } \\
\text { en la ciudad de La Haya (países } \\
\text { Bajos). }\end{array}$ & $\begin{array}{l}\text { - Tribunal } \\
\text { - Justicia } \\
\text { - Imparcialidad } \\
\text { - Severidad } \\
\text { - Ley } \\
\text { - Arbitraje }\end{array}$ \\
\hline Convemar(Figura actor) & $\begin{array}{l}\text { Convención de las Naciones Uni- } \\
\text { das para el Derecho del Mar. Es } \\
\text { uno de los instrumentos jurídicos } \\
\text { más completos del derecho in- } \\
\text { ternacional sobre soberanía, ju- } \\
\text { risdicción, utilización y obligacio- } \\
\text { nes de los Estados en relación } \\
\text { con los océanos.Establece que el } \\
\text { límite marítimo entre países ve- } \\
\text { cinos debe fijarse a partir de una } \\
\text { línea equidistante que nazca en } \\
\text { la frontera entre ambos países. }\end{array}$ & $\begin{array}{l}\text { - Seriedad } \\
\text { - Compromiso } \\
\text { - Regulación } \\
\text { - Arbitrio } \\
\text { - Legalidad }\end{array}$ \\
\hline
\end{tabular}

Fuente: Elaborado por los autores para la investigación. 


\begin{tabular}{|c|c|}
\hline & SITUACIONES DISCURSIVAS \\
\hline SITUACIÓN DISCUSIVA (1) & $\begin{array}{l}\text { La primera situación discursiva muestra a la figura actor La Moneda, en } \\
\text { representación del concepto de gobierno de Chile, como una institu- } \\
\text { ción política desconcertada ante la iniciativa impulsada por el gobierno } \\
\text { de Perú, la cual promueve una reforma a los actuales puntos de limita- } \\
\text { ción marítima entre ambos países.Lo anterior motiva a la figura actor } \\
\text { del Presidente Ricardo Lagos a coordinarse y movilizarse mediante una } \\
\text { ofensiva diplomática, en búsqueda de apoyo y consenso con el resto } \\
\text { de los países de la Región y, de esta forma, convertir la negación a la } \\
\text { propuesta peruana, en una insignia multilateral.Es por ello, que dicha } \\
\text { figura actor, mediante su recorrido figurativo, dentro del discurso ad- } \\
\text { quiere, por un lado, los valores de preocupación y prevención y, por } \\
\text { otro, los de inseguridad e inestabilidad, por cuanto los nuevos puntos } \\
\text { limítrofes que plantea la Ley de Líneas de Base desestabiliza no sólo la } \\
\text { seguridad de Chile sobre el territorio marítimo sobre el cual ejerce com- } \\
\text { pleta soberanía, sino que, además, promueve la inseguridad y desequi- } \\
\text { librio de la armonía diplomática dentro del contexto latinoamericano. }\end{array}$ \\
\hline SITUACIÓN DISCUSIVA (2) & $\begin{array}{l}\text { La segunda situación discursiva que se presenta en la noticia analizada } \\
\text { muestra la figura actor del Secretario general de Gobierno, Osvaldo } \\
\text { Puccio, en su calidad de vocero de la Administración del Presidente } \\
\text { Lagos, como una autoridad que invita al estudio y análisis de la } \\
\text { situación.De esta forma, expresa su preocupación ante la situación que } \\
\text { se ha creado con el país vecino, pero ratifica que Chile continuará su } \\
\text { defensa enmarcado dentro del contexto de la legalidad y seguridad que } \\
\text { ofrecen los tratados internacionales concretados con Perú. A partir de } \\
\text { su recorrido figurativo dentro del discurso, Puccio genera valores de } \\
\text { concilio y calma. }\end{array}$ \\
\hline SITUACIÓN DISCUSIVA (3) & $\begin{array}{l}\text { La tercera situación discursiva hace referencia a la estrategia diplomáti- } \\
\text { ca impulsada por el gobierno de Perú, luego de que dicha figura actor } \\
\text { aprovecha la tensión generada por la aprobación de la ley, para llevar el } \\
\text { caso ante una corte internacional que apoye la causa, queja y demanda } \\
\text { limeña.De esta forma, la figura actor de Torre Tagle adquiere los valores } \\
\text { temáticos de conflicto, quebrantamiento, tensión, unilateralidad y } \\
\text { hostilidad.Con respecto a este último valor, cabe señalar que el clima } \\
\text { hostil creado por la demanda limeña involucra a otros gobiernos regio- } \\
\text { nales, tales como Ecuador, el cual proyecta un sentimiento de inestabi- } \\
\text { lidad y preocupación ante el desarrollo del impasse.Por tanto, Ecuador, } \\
\text { como figura actor, es percibido como una figura implicada dentro del } \\
\text { conflicto y, por ende, genera el valor de inseguridad.A raíz de la preten- } \\
\text { sión peruana por encauzar el tema marítimo hacia un juicio internacio- } \\
\text { nal, surge dentro de esta misma situación discursiva, la figura actor de } \\
\text { la Convención de las Naciones para el Derecho del Mar (Convemar). Es } \\
\text { así como, a partir del recorrido figurativo, esta figura adquiere valores } \\
\text { temáticos de seriedad, compromiso, regulación, arbitrio y legalidad, por } \\
\text { cuanto fija los puntos de límites marítimos entre países a partir de una } \\
\text { línea equidistante que nazca de la frontera entre ambos. }\end{array}$ \\
\hline
\end{tabular}




\begin{tabular}{|c|c|}
\hline SITUACIÓN DISCUSIVA (4) & $\begin{array}{l}\text { En la cuarta situación discursiva encontramos las figuras actores de } \\
\text { Bolivia y el Tratado de Zona de Delimitación Marítima de } 1952 \text { firmado } \\
\text { entre Chile, Perú y Ecuador.En primer lugar, debemos referirnos a Boli- } \\
\text { via como una figura actor que se ve envuelta y probablemente perjudi- } \\
\text { cada a raíz del impasse diplomático surgido entre Chile y Perú. Es así } \\
\text { como esta figura actor adquiere valores de víctima, perjuicio, preocupa- } \\
\text { ción, intranquilidad e incertidumbre tras la posibilidad de ver merma- } \\
\text { dos sus deseos de obtener acceso al mar.En segundo lugar, el Tratado } \\
\text { de Zona de Delimitación Marítima de 1952, dentro del discurso, es per- } \\
\text { cibido como una figura actor que pone en evidencia la complicidad, el } \\
\text { pacto y acuerdo entre tres países de la Región, entre ellos Chile y Ecua- } \\
\text { dor, que de una u otra forma ven menoscabada su jurisdicción marítima } \\
\text { frente a la iniciativa de Perú tras la aprobación de la Ley de Líneas de } \\
\text { Base.Es por ello que el Tratado, a partir de su recorrido figurativo, gene- } \\
\text { ra valores de formalismo, exactitud y legalidad, por cuanto respalda el } \\
\text { reclamo del gobierno de Chile, luego que esta figura actor invoque la } \\
\text { oficialidad y rigurosidad del acuerdo. }\end{array}$ \\
\hline SITUACIÓN DISCUSIVA (5) & $\begin{array}{l}\text { En la quinta situación discursiva se abstraen las consecuencias que } \\
\text { conlleva, dentro del marco latinoamericano y chileno, la aprobación } \\
\text { por parte del Congreso limeño. Es así como surgen las figuras actores } \\
\text { de La Moneda, como opositor a la iniciativa peruana; y Perú, como } \\
\text { provocador de un clima de tensión y hostilidad.El gobierno de Chile } \\
\text { (representado por La Moneda), tal como se describe en la situación } \\
\text { discursiva primera, adquiere valores de preocupación, análisis e ines- } \\
\text { tabilidad frente a la resolución que tendrá el impasse diplomático. En } \\
\text { tanto, Perú es visto como una figura actor que, a partir de su recorrido } \\
\text { figurativo, provoca inseguridad dentro del concierto diplomático in- } \\
\text { ternacional, situando en un plano de inestabilidad y desconcierto a } \\
\text { más de un gobierno regional. }\end{array}$ \\
\hline SITUACIÓN DISCUSIVA (6) & $\begin{array}{l}\text { La sexta situación discursiva se encuentra en estrecha relación con la } \\
\text { primera, por cuanto trata sobre la preocupación que le compete al go- } \\
\text { bierno de Chile respecto a la entrada en vigencia de la respectiva ley. De } \\
\text { la misma forma, dentro de esta situación, surge una figura actor clave } \\
\text { en cuanto a la estrategia comunicacional y diplomática impulsada por } \\
\text { Chile: la Cumbre de las Américas, figura que adquiere valores, entre } \\
\text { otros, de apoyo, compromiso, multilateralismo y negociación, ya que } \\
\text { los Presidentes de los países americanos se reúnen para tratar los te- } \\
\text { mas contingentes de la Región. A raíz de ello, podemos decir que la } \\
\text { figura de la Cumbre refuerza la importancia y magnitud que adquiere el } \\
\text { conflicto limítrofe, tanto para los países implicados, como para la esta- } \\
\text { bilidad del resto de los gobiernos.De esta forma, el Presidente de Chile, } \\
\text { Ricardo Lagos, irrumpe en el discurso como una figura imponente, la } \\
\text { cual exige y espera que el conflicto sea mediado por instrumentos lega- } \\
\text { les, y asimismo, advierte y desafía al Presidente de Perú, Alejandro Toledo } \\
\text { que Chile no permitirá las modificaciones limítrofes y muestra abierta- } \\
\text { mente su rechazo hacia la iniciativa limeña. }\end{array}$ \\
\hline
\end{tabular}




\section{SITUACIÓN DISCUSIVA (7)}

\begin{abstract}
Finalmente, en la séptima situación discursiva, surgen las figuras actores del canciller peruano, Manuel Rodríguez Cuadros y la ex ministra de Relaciones Exteriores, Soledad Alvear. De la misma forma, ambas figuras se relacionan mediante la acción de otras dos figuras actores: el Libro Blanco de Defensa Nacional de Perú y el Tribunal Internacional de La Haya. Ambos actores sociales, mediante sus recorridos figurativos, legitiman sus respectivas acciones dentro del discurso y dentro del marco del clima tenso que provoca la iniciativa peruana de modificar las fronteras marítimas con las cuales limita con Chile.La figura actor de Manuel Rodríguez Cuadros es comprendida como un actor que plantea un consenso tras proponer el sometimiento de la pugna ante un arbitraje internacional. Por lo mismo, el recorrido de este actor dentro del discurso genera valores de tensión, conflicto, desafío y hostilidad, puesto que reta a Chile en caso de que éste manifieste su oposición ante el anhelo peruano de ejercer soberanía en territorio marítimo chileno.De esta forma, Perú (a través del recorrido figurativo de su canciller), se muestra como un país desafiante el cual no tolera la oposición o resistencia por parte del gobierno chileno hacia la modificación marítima. En tanto, Chile es percibido como un país, que pese a manifestar su disconformidad, negación, oposición y disgusto ante la iniciativa de Toledo, tiende a desdramatizar la tensión.
\end{abstract}

Fuente: Elaborado por los autores para la investigación.

\section{Dimensión Semiótica}

Cuadro 1.0

Inseguridad

complementariedad

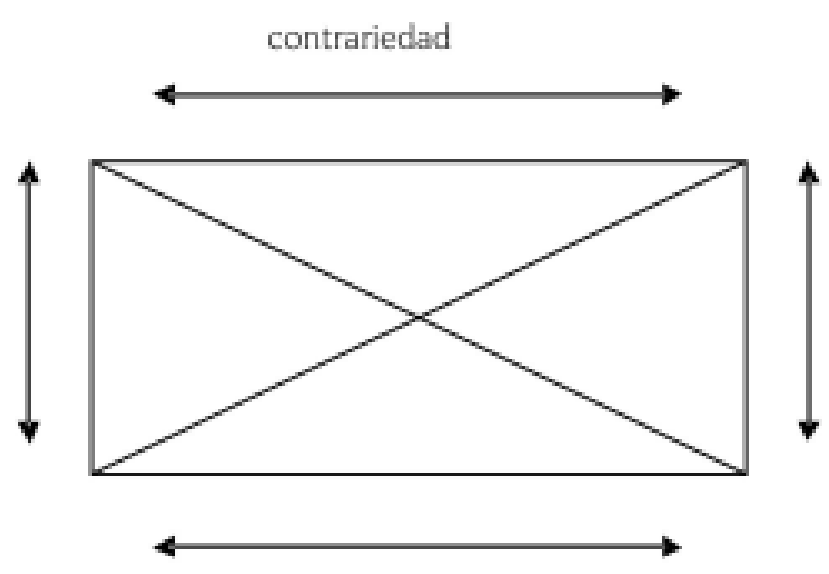

Estabilidad

Seguridad

Inestabilidad

Chile, como país y como gobierno, se

La oposición «Inseguridad - Estabilidad», presente en la noticia, tiene la significación dada por la figura actor del gobierno de Chile, figura que adquiere la respectiva significación debido a la amenaza y tensión que refleja, dentro del discurso, la figura actor del gobierno peruano. manifiesta como un actor que, pese a reaccionar diplomáticamente frente al hecho de ver amenazada su soberanía marítima, la ley impulsada por el gobierno de Perú logra desestabilizar las estructuras del respectivo gobierno, por cuanto la iniciativa de Lima 
sorprende a Chile y lo sitúa en un escenario de incertidumbre e inestabilidad ante el desencadenamiento de hechos y dentro de un clima de tensión y animosidad entre Chile y Perú.

Frente a esta situación, el gobierno chileno organiza rápidamente la ofensiva mediante la cual abordará y enfrentará el impasse generado por la aprobación unilateral de la Ley de Líneas de Base por parte del Congreso peruano.

Tal como se mencionó con anterioridad, la figura actor de Chile o del gobierno chileno surge dentro del discurso como una figura que se ve perjudicada ante lo que pareciere considerarse un capricho por parte del gobierno vecino y, que sin duda alguna, convoca y abre nuevamente la puerta de enemistad histórica existente entre ambos países.

Es por ello que la figura actor del gobierno peruano es quien legitima el valor temático que genera la figura actor del gobierno de Chile dentro del discurso.
La inseguridad, tensión e inestabilidad que el respectivo proyecto de ley crea dentro de la Administración de Lagos permite observar, a su vez, el nivel de comunicación y coordinación entre los ministros de gobierno con el objetivo de diseñar de forma rápida las líneas sobre las cuales se cimienta la ofensiva chilena.

Asimismo, la inestabilidad que refleja Chile ante este inesperado impasse diplomático reafirma el sentimiento de patriotismo y de defensa de la soberanía nacional sobre la zona del Pacífico sobre la cual Chile posee plena jurisdicción. Si bien Chile refleja preocupación frente a la aprobación de la Ley de Líneas de Base, la situación generada por Perú permite que dentro del discurso Chile adopte un rol de estratega, de análisis y de diplomacia.

De la misma forma, la condición de inseguridad que representa el gobierno chileno en primera instancia, no sólo involucra la seguridad y soberanía de Chile, sino que también sitúa las relaciones diplomáticas con Perú en un escenario de inseguridad, hostilidad y antagonismo.

Cuadro 2.0

Tensión

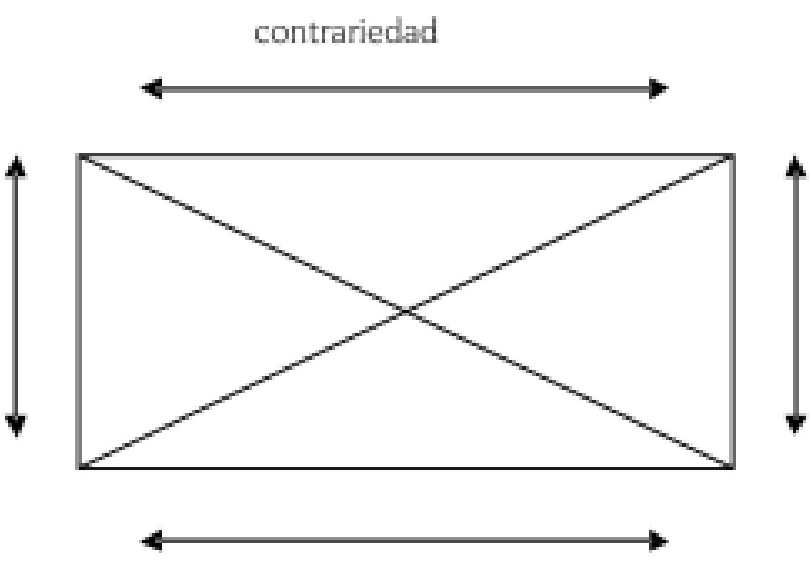

Armonía

complementariedad

No Armonía

No Tensión

Fuente: Elaborado por los autores para la investigación. 
Una segunda relación de oposición presente en el texto analizado está dada por la «Tensión - Armonía», donde la significación de dicha relación se genera por las figuras actores del Presidente de Chile, Ricardo Lagos y el Presidente de Perú, Alejandro Toledo.

Al igual que en la relación anteriormente descrita, la aprobación de la Ley de Líneas de Base desencadena un clima de tensión entre los Mandatarios de los países que enfrentan el conflicto marítimo.

Es así como la figura actor del Presidente Alejandro Toledo, a lo largo del discurso, genera valores de animadversión y de adversidad hacia su homólogo chileno, lo cual crea en torno a las relaciones bilaterales, un clima de tensión y de conflicto. En tanto, el Presidente chileno es visto como un político que se ve directamente amenazado fren- te a la iniciativa peruana y que, por lo mismo, se percibe como una víctima de la rivalidad creada por Toledo.

Por ello, la aprobación de la ley que modifica la delimitación marítima entre Chile y Perú y que pone en tela de juicio la soberanía chilena sobre su territorio marítimo es concebida como un capricho por parte del gobierno de Toledo, el cual rompe la armonía, buena voluntad y diplomacia entre los respectivos países.

Lo anterior reafirma la posición de la figura actor de Perú, como un país que produce inestabilidad y desconcierto dentro de la Administración de Ricardo Lagos, por cuanto valida los valores temáticos de unilateralidad, infracción y tensión, que dicha figura adquiere a partir de su recorrido figurativo dentro del discurso elaborado por La Tercera.

Cuadro 3.0

Justicia

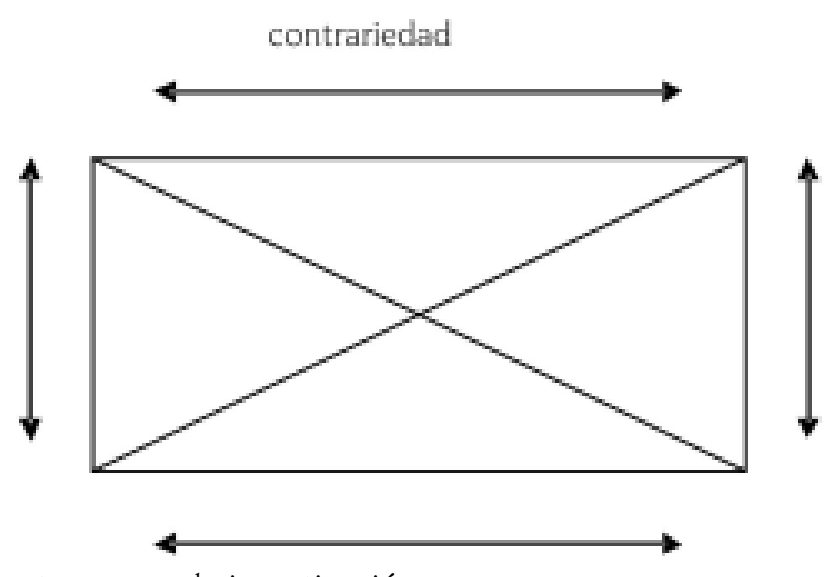

Arbitrariedad

complementariedad

\section{Legalidad}

ara la investigación.

En el cuadro (3.0) se muestra un análisis de la relación de contrariedad dada por «usticia - Arbitrariedad», la cual adquiere la significación fundamental en el discurso, ya que la figura del Tribunal Inter- nacional de La Haya se convierte en una herramienta de legalidad, por cuanto ambas figuras actores (Chile y Perú) hacen referencia a ella como una instancia de arbitraje. 
Asimismo, la Convención para el Derecho del Mar, de la Organización de las Naciones Unidas, es considerada por el gobierno peruano como un elemento central dentro de su estrategia jurídica, estrategia diseñada a partir de la aprobación de la Ley de Líneas de Base. De esta forma, frente a la posibilidad de recurrir a La Haya, Perú propone consultar a la Convemar, por cuanto estratégicamente le conviene, ya que de acuerdo con el discurso esgrimido por el gobierno peruano, ésta fallaría a favor de la causa peruana.

Por otro lado, dentro del valor de «Justicia», en el discurso también se hace referencia a aquellas herramientas jurídicas que respaldan la postura de oposición y denuncia asumida por el gobierno de Chile. Dentro de ellas, se hace mención al tratado de delimitación marítima firmado por Chile, Perú y Ecuador en el año 1952.
Frente al valor de justicia que representan las figuras actores descritas con anterioridad, podemos señalar que la figura de la Ley de Líneas de Base se contrapone a la legalidad que caracteriza al Tribunal de La Haya, la Convemar y el Tratado de 1952, por cuanto es considerada dentro del discurso, como una medida unilateral y arbitraria por parte del Congreso peruano.

La medida adoptada a raíz de la iniciativa propuesta por Alejandro Toledo, Presidente de Perú, invalida los puntos que promul ga el Tratado de delimitación marítima, ya que desconoce la validez que éste tiene dentro del marco jurídico internacional. Frente a esto, la aprobación de la Ley de Líneas de Base y la denuncia por parte del gobierno chileno, respecto a la infracción cometida por Perú, rectifican la tensión y hostilidad generadas por el impasse diplomático entre Lima y Santiago.

Cuadro 4.0

Conflicto

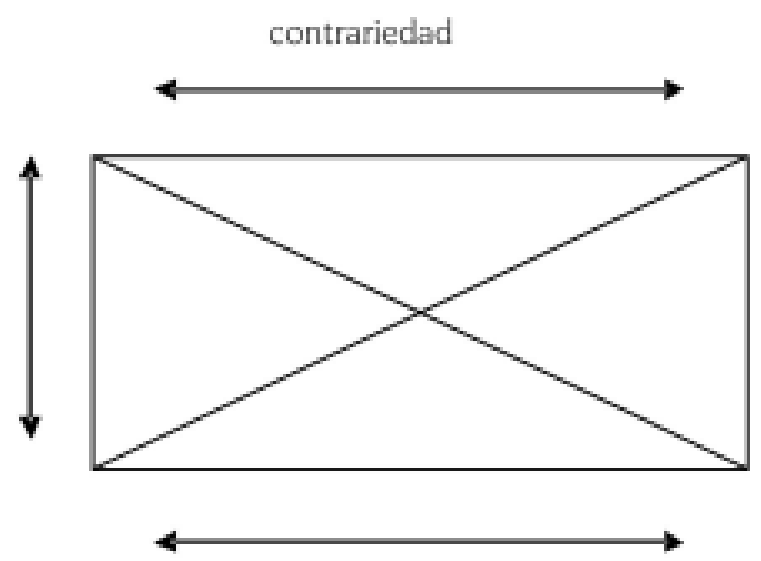

Bienestar

complementariedad

Malestar

de la figura actor de Perú, por ser éste el elemento que germina la crisis y el impasse diplomático con el gobierno chileno. tar», lógica que cobra significación, por un lado, a partir del recorrido figurativo 
Dicha relación presenta a las figuras actores de Chile y Perú en una posición de antagonismo y rivalidad, lo cual desemboca en un clima hostil y de enemistad. De la misma forma, a raíz de la iniciativa impulsada por el gobierno peruano, la figura de Chile es percibida como la de un país y gobierno víctima de la unilateralidad y tensión que genera Perú al adoptar sin previas negociaciones la intención de modifi- car los puntos marítimos en los cuales limitan los respectivos países.

Asimismo, Perú refleja dentro del discurso los valores de rivalidad y antagonismo respecto a Chile y, con ello, legitima la posición de preocupación, inestabilidad e inseguridad del gobierno de Chile frente a la posibilidad de perder su soberanía sobre el océano Pacífico.

\section{Dimensión factual}

\begin{tabular}{|l|l|}
\hline DISCURSO EMPIRISTA & $\begin{array}{l}\text { Hay presentación de datos empíricos cuando se hace mención a } \\
\text { los tratados regionales firmados por Perú en 1952. Además, se } \\
\text { menciona en el discurso las consecuencias que tiene la acción } \\
\text { peruana para los intereses de Bolivia. }\end{array}$ \\
\hline FABRICACIÓN DEL CONSENSO & $\begin{array}{l}\text { Chile asume la oposición esperada ante la acción del Perú y se } \\
\text { busca evidenciar la contradicción legal en la que incurre el país } \\
\text { vecino al postular una ley que contraviene los acuerdos limítro- } \\
\text { fes suscritos entre Chile, Perú y Ecuador. }\end{array}$ \\
\hline DETALLES EN LA NARRACIÓN & $\begin{array}{l}\text { El discurso presenta descripciones detalladas, por una parte, } \\
\text { sobre los reclamos que Perú ha levantado en ocasiones anterio- } \\
\text { res y, por otra, acerca de la reunión que sostuvo el Presidente } \\
\text { Ricardo Lagos con sus autoridades ministeriales. Estos detalles } \\
\text { denotan el carácter de urgencia, importancia y conflicto en las } \\
\text { relaciones entre Chile y Perú. }\end{array}$ \\
\hline MAXIMIZACIÓN / \\
MINIMIZACIÓN & $\begin{array}{l}\text { Se clasifica como «delicada» la situación actual y, por lo tanto, } \\
\text { se asume la amenaza y tensión evidente que refleja, dentro } \\
\text { del discurso, la propuesta peruana que busca una redefinición } \\
\text { maritima. }\end{array}$ \\
\hline NORMALIZACIÓN / & $\begin{array}{l}\text { La postura de Chile se configura a partir de los conceptos de } \\
\text { cautela, estrategia, análisis y legalidad (normal), frente al sentido } \\
\text { que se refuerza sobre la posición peruana, la cual se explica como } \\
\text { ilegal y conflictiva. }\end{array}$ \\
\hline
\end{tabular}

Fuente: Elaborado por los autores para la investigación. 


\section{CONSIDERACIONES FINALES}

La propuesta metodológica desarrollada en este trabajo da cuenta de cómo la representación positiva de Chile, en los discursos publicados por los diarios El Mercurio y La Tercera, legitima el valor de conflicto y hostilidad que representa dentro del discurso la figura de Perú mediante la aprobación de la Ley de Líneas de Base. De esta forma, la ley impulsada por el gobierno peruano adquiere gran predominancia en el desencadenamiento del impasse, por cuanto se convierte en el factor que da inicio al conflicto marítimo por considerarse como una medida unilateral y arbitraria ejecutada por el ex Presidente peruano, Alejandro Toledo.

Así los datos obtenidos por medio del análisis del corpus nos permiten concluir que la representación del mundo, particularmente del Perú, ha sido construida sobre la base de elementos de significación vinculados al papel conflictivo del país limítrofe, lo que produce una representación textual de into- lerancia acerca del Otro que es vinculado con implicaciones de carácter negativo para el desarrollo de Chile y donde las manifestaciones políticas y mediáticas de diversa índole, llevadas a cabo por un sujeto o colectivo que representa a la nación peruana, se clasifican como acciones ilegales, arbitrarias y ofensivas que atentan contra el orden socioeconómico y político establecido para el bienestar del pueblo chileno.

Entonces, es indispensable entender que la acción de construir y representar un fenómeno determinado a partir de la cobertura mediática de un conflicto entre países latinoamericanos, pretende, por una parte, establecer un control social por parte de las instituciones de poder y, por otra, otorgar un sentido homogéneo al mundo social como mecanismo utilizado para mantener categorías históricas acerca del Otro. En consecuencia, la acción discursiva de los medios de comunicación social tiende a producir una ultrasimplificación sígnica de un Estado-nación por medio de la producción de esquemas interpretativos capaces de facilitar al colectivo dominante la distinción entre el «Nosotros» y los «Otros».

\section{NOTAS}

$1 \quad$ Este trabajo presenta algunos resultados y la propuesta de análisis complejo del discurso, utilizado en la investigación «Representación mediática del Perú en la prensa chilena. Descripción de las lógicas y dinámicas del discurso periodístico en el marco del conflicto limítrofe-marítimo de 2005), realizada en el Programa de Magíster en Ciencias de la Comunicación, Departamento de Lenguas, Literatura y Comunicación, Facultad de Educación y Humanidades, Universidad de La Frontera. Temuco, Chile.Email:magcom@ufro.cl

2 Concepto utilizado en la investigación para describir a todo Estado-nación o grupo de individuos que no son parte del Estado de Chile. 


\section{REFERENCIAS BIBLIOGRÁFICAS}

Courtés, Joseph. 1995. Análisis semiótico del discurso: Del enunciado a la enunciación. Madrid: Gredos.

Del Valle Rojas, Carlos. 2006. Comunicación participativa, Estado-nación y democracia: Discurso, tecnología y poder. Temuco: Ediciones Universidad de la Frontera.

Giroud, Jean-Claude y Panier, Louis. 1988. Semiótica. Navarra: Verbo Divino.

Lefebvre, Henry. 1983. La presencia y la ausencia. Contribución a la teoría de las representaciones. México: Fondo de Cultura Económica.

Martín Serrano, Manuel. 1986. La producción social de comunicación. Madrid: Alianza.

Potter, Jonathan. 1998. La representación de la realidad. Discurso, retórica y construcción social. Barcelona: Paidós.

Van Dijk, Teun A. 1999. Ideología: Un enfoque multidisciplinario. Barcelona: Gedisa. 